\title{
Suprapubic Bladder Aspiration in Diagnosis of Urinary Tract Infection
}

\author{
R. R. BAILEY,* M.B., CH.B., M.R.A.C.P. ; P. J. LITTLE, $†$ M.B., CH.B., M.R.C.P.
}

Brit. med. F., 1969, 1, 293-294

\begin{abstract}
Summary: Suprapubic aspiration of the bladder has $\checkmark$ proved a safe and reliable method of collecting urine for culture. It avoids contamination of the specimen and dispenses with the need for colony counts, because the isolation of any organism indicates bladder bacteriuria. In addition, urine collected in this way can be kept at $4^{\circ} \mathrm{C}$. or at room temperature for up to 10 days before it is cultured.
\end{abstract}

\section{Introduction}

The diagnosis of true urinary infection in women remains a difficult problem in clinical practice. Quantitative cultures often make it possible to distinguish between contaminating organisms and those which are present and multiplying in the urine at the time of micturition. False positives due to contamination do occur. Although the presence of infection can sometimes be confirmed by repeating the culture of a midstream specimen, those women who produce contaminated specimens tend to do so recurrently.

The method of obtaining a specimen of urine by suprapubic aspiration from the bladder was first reported by Guze and Beeson (1956). The technique has now been shown to be quite safe in premature infants, neonates, children, and adults, including antenatal patients (Beard, McCoy, Newton, and Clayton, 1965; Nelson and Peters, 1965; Pryles, 1965; Stamey, Govan, and Palmer, 1965 ; Newman, O'Neill, and Parker, 1967 ; McFadyen and Eykyn, 1968).

A midstream specimen of urine if not kept at $4^{\circ} \mathrm{C}$. must be examined within one hour of voiding, to avoid multiplication of contaminants (Kass, 1956).

The present investigation was carried out to see if the same urgency was required in the examination of urine specimens obtained by suprapubic aspiration of the bladder.

\section{Methods}

The patients on whom bladder aspiration was to be performed were instructed to drink about $500 \mathrm{ml}$. of fluid and refrain from voiding for two hours before the procedure. Patients arriving at the clinic with an empty bladder were given $10-20 \mathrm{mg}$. of intravenous frusemide.

An all-metal 22 -gauge $1 \frac{1}{2}$-in. $(3 \cdot 8-\mathrm{cm}$.) needle attached to a $5-\mathrm{ml}$. disposable syringe was used. The skin was swabbed with antiseptic. The needle was passed with one movement into the bladder $1-2 \mathrm{~cm}$. above the symphysis pubis in the midline. Local anaesthesia was not used.

The specimens were kept in the syringes in which they were collected, with corks placed on the ends of the needles. Urine specimens were stored in the syringes under various temperature conditions for 10 days. On each day part of each specimen was placed on nutrient agar and MacConkey's medium and cultured for 18 hours at $37^{\circ} \mathrm{C}$.

\footnotetext{
* Senior Registrar.

t Renal Physician.

Department of Renal Medicine; Christchurch Hospital, Christchurch, New Zealand.
}

\section{Results}

Sixty-one initially sterile specimens were kept at either $4^{\circ} \mathrm{C}$., room temperature, or $37^{\circ} \mathrm{C}$. (Table I). Fifty-nine specimens remained sterile throughout the 10 -day period. Two urines became infected. These were obtained and studied concurrently and both became infected on the third day with a Gram-positive coccus.

\begin{tabular}{|c|c|c|c|}
\hline \multicolumn{2}{|l|}{ Storage } & $\begin{array}{l}\text { No. of } \\
\text { Specimens }\end{array}$ & $\begin{array}{l}\text { No. Infected on or } \\
\text { before Day } 10\end{array}$ \\
\hline $\begin{array}{l}4^{\circ} \mathrm{C} \\
\text { Room temperature } \\
37^{\circ} \mathrm{C} . \quad \ldots\end{array}$ & $\ddot{0}$ & $\begin{array}{l}20 \\
21 \\
20\end{array}$ & $\begin{array}{l}1 \\
0 \\
1\end{array}$ \\
\hline Total .. & $\ldots$ & 61 & 2 \\
\hline
\end{tabular}

Forty-two infected urine specimens were kept at either $4^{\circ} \mathrm{C}$. or room temperature and cultured daily for 10 days (Table II). In only three specimens did the organisms cease to grow. Growth stopped in these three after the fifth day. Specimens containing Gram-negative bacilli continued to grow organisms in large numbers throughout the 10-day period.

TABLE II.-Infected Urine Specimens

\begin{tabular}{|c|c|c|c|}
\hline Storage & & $\begin{array}{c}\text { No. of } \\
\text { Specimens }\end{array}$ & $\begin{array}{l}\text { No. Sterile on or } \\
\text { before Day } 10\end{array}$ \\
\hline $\begin{array}{l}4^{\circ} \mathrm{C} . \quad . . \quad \ldots \\
\text { Room temperature }\end{array}$ & $\because$ & $\begin{array}{l}21 \\
21\end{array}$ & $\begin{array}{l}2 \\
1\end{array}$ \\
\hline Total .. & .. & 42 & 3 \\
\hline
\end{tabular}

\section{Discussion}

It is considered unjustifiable to catheterize the bladder to obtain a specimen of urine for culture (Brumfitt, Davies, and Rosser, 1961). Though such a technique infrequently leads to false-positive results, it does introduce bacteria into the bladder and it is uncomfortable and time-consuming.

The delay which follows repeating the culture of a midstream specimen of urine and the difficulties of interpretation make this an unsatisfactory investigation in many clinical situations. In the puerperium and after vaginal surgery differentiating urinary from genital tract infection can be a most difficult problem at a time when vaginal contamination and urethral disturbance from trauma is maximal.

The technique of bladder puncture is simple and no more uncomfortable than a venepuncture. All reports testify to the safety of the procedure. No urine or amniotic fluid leaks from the puncture site and no uterine damage or increase in abortion rate has been reported (McFadyen and Eykyn, 1968). Microscopical haematuria may occasionally be observed for a few hours after bladder puncture.

It is most important that the bladder is fully distended before aspiration is attempted. The patient's sensation of bladder fullness is sometimes misleading, but it can be confirmed by palpation or occasionally in the very obese by bimanual examination. 
In the series of 2,500 aspirations without complication reported by Stamey et al. (1965), one-third had a bacterial count of less than 100,000 organisms per $\mathrm{ml}$. The same workers showed that hydration reduced the bacterial counts to the 10,000-100,000 organisms per ml. range, but not lower, and that in $5-6 \%$ of infected urines a mixed growth was obtained.

The problem of satisfactory urine collection is a major one both inside and outside the hospital. The technique described here reduces the extra work necessary in carrying out multiple quantitative cultures, especially in paediatric, post-pantum, post-surgical, paraplegic, and elderly patients. Bladder puncture is a most convenient technique for use in the consultingroom, for, as we have shown, the specimen could be left lying about at room temperature and delivered to the laboratory for culture when convenient. In addition such specimens can be sent to the laboratory by post when packaged appropriately.
We should like to thank the Canterbury Medical Research Foundation for financial assistance.

Requests for reprints should be addressed to Dr. P. J. Little.

\section{REFERENCES}

Beard, R. W., McCoy, D. R., Newton, J. R., and Clayton, S. G. (1965) Lancet, 2,610 .

Brumfitt, W., Davies, B. I., and Rosser, E. ap I. (1961). Lancet, 2, 1059. Guze, L. B., and Beeson, P. B. (1956). New Engl. F. Med., 255, 474.

Kass, E. H. (1956). Trans. Ass. Amer. Phycns, 69, 56.

McFadyen, I. R., and Eykyn, S. J. (1968). Lancet, 1, 1112

Nelson, J. D., and Peters, P. C. (1965). Pediatrics, 36, 132.

Newman, C. G. H., O'Neill, P., and Parker, A. (1967). Brit. med. f., 2, 277.

Pryles, C. V. (1965). Pediatrics, 36, 128.

Stamey, T. A., Govan, D. E., and Palmer, J. M. (1965). Medicine (Baltimore), 44, 1.

\title{
Epilepsy and Oral Contraception
}

\author{
MICHAEL ESPIR,* M.A., M.B., M.R.C.P. ; M. E. WALKER, † M.A., M.B., M.R.C.P. ; \\ JUNE P. LAWSON, $\ddagger$ M.B., CH.B., D.OBST.R.C.o.G.
}

Brit. med. F., 1969, 1, 294-295

Cummary : A controlled cross-over trial in 20 epileptic $\checkmark$ women, receiving regular anticonvulsant therapy showed that an oral contraceptive with a low oestrogen/ progestogen content had no significant effect on the average frequency of fits compared with identical dummy tablets.

\section{Introduction}

The particular relevance of oral contraception to patients with epilepsy is readily apparent, yet little information is available about the effects of the different contraceptive pills in such cases (Brit. med. F., 1967). There are theoretical grounds for suspecting that oral contraceptive drugs might influence the control of fits, and Mears (1965) and the World Health Organization (1966) recommend careful evaluation of patients with epilepsy before oral contraception is started. Isolated case reports have produced conflicting evidence and no controlled study is available. The purpose of this paper is to report the effect of a particular contraceptive pill (Norinyl-1\$) on a group of epileptic women.

\section{Material and Methods}

Twenty-three women with epilepsy and having menstrual periods were chosen. All had been investigated in the departments of neurology and electroencephalography in Leicester between 1960 and 1967. We included only those who had been on an anticonvulsant regimen which had been unchanged for several months or years and which appeared to be the most suitable that could be offered in each case. Patients already receiving oral contraception or regular treatment with drugs other than anticonvulsants were excluded, and care was taken to ensure that none had a past history of cardiac, renal, or

- Consultant Neurologist, Leicester Royal Infirmary.

t Neurological Registrar, Leicester Royal Infirmary.

\# Clinical Advisor, Syntex Pharmaceuticals Ltd.

forinyl-1 contains $0.05 \mathrm{mg}$. of mestranol and $1 \mathrm{mg}$. of norethisterone. thrombotic disease. Once a patient was regarded as suitable for the trial she was told that we were attempting to evaluate the effect of a drug which, though it had been used in other conditions, had not previously been used specifically for epilepsy. She was told that it was a hormone preparation, which had an effect on menstruation and fertility. Alternate patients were given Norinyl-1 and told to take one tablet each evening for 21 consecutive days out of 28 , and at the end of three such monthly cycles a dummy tablet, identical in appearance, was substituted unbeknown to the patient, who followed the same regimen for another three months. The other patients took the dummy tablet and Norinyl-1 in the reverse order. All patients continued to take their established anticonvulsant therapy. All patients were provided with a special card containing three squares for each day of the trial on which they recorded the taking of tablets, menstrual loss, and the number and type of any epileptic attacks. They were seen and their cards checked at monthly intervals.

\section{Results}

Three patients defaulted at an early stage, leaving 20 who completed the trial. Their main clinical and electroencephalographic (E.E.G.) features are shown in the Table, with the frequency of fits before and during the trial in each case. This shows that two patients were free of fits during the trial period. In two instances there were notable discrepancies between the number of fits during the trial and the average incidence previously. One patient (Case 19) receiving Norinyl-1 had 38 attacks during a one-week period when she was suffering from gastroenteritis. An increase in fit frequency also occurred in a patient (Case 7) taking the dummy preparation, when she developed a boil on her face with pronounced cellulitis. Overall there was a remarkable constancy in the total number of fits during and before the two periods of the trial. The first seven patients (Cases 1-7) had fewer fits while taking Norinyl-1, and the last 11 (Cases 10-20) had fewer fits on the dummy. By $\chi^{2}$ analysis this difference is not greater than might be 